\title{
Converting a Lens to Its Equivalent as Referenced to Pupil Imaging
}

\author{
Hyun Jin Bang and Jong Ung Lee ${ }^{\dagger}$ \\ Department of Laser and Optical Information Engineering, Cheongju University, 298 Daeseong-ro, Sangdang-gu, \\ Cheongju 360-764, Korea
}

(Received December 18, 2013; Revised manuscript January 29, 2014; Accepted January 29, 2014)

\begin{abstract}
The equivalent of a thick lens is a lens which has the same power of refraction and paraxial imaging characteristics for a reference ray, but with a different axial thickness. In this study, thick lenses of an optical system were converted to their equivalent lenses referenced to pupil imaging. Aberration changes due to the lens conversion were compared to the general equivalent lens conversion referenced to object imaging.
\end{abstract}

Keywords: Equivalent lens, Lens conversion, Pupil imaging, Optical system design OCIS codes: (080.2740) Geometric optical design; (080.3630) Lenses; (220.3620) Lens system design

\section{동의 결상을 기준으로 한 등가렌즈 변환에 대한 연구 방현진· 이종웅 ${ }^{\dagger}$}

청주대학교 레이저광정보공학과

(i) 360-764 충북 청주시 상당구 대성로 298

(2013년 12월 18일 받음, 2014년 1월 29일 수정본 받음, 2014년 1월 29일 게재 확정)

등가렌즈는 굴절능과 특정한 기준광선에 대한 근축광학적 특성은 같고, 축상두께가 다른 렌즈이다. 이 연구에서는 동의 결상을 기준으로 광학계의 두꺼운 렌즈를 등가렌즈로 변환하고 일반적으로 사용되던 물체의 결상을 기준으로 등가렌즈로 변환한 경우와 Seidel 수차의 변화를 비교하였다.

Keywords: 등가렌즈, 렌즈변환, 동의 결상, 광학설계

OCIS codes: (080.2740) Geometric optical design; (080.3630) Lenses; (220.3620) Lens system design

\section{I. 서 론}

등가렌즈(equivalent lens)는 렌즈의 두께와 곡률은 다르지 만, 근축광학적 특성과 전체 굴절능이 동일한 렌즈를 의미하 며, 두꺼운 렌즈는 등가렌즈 변환을 이용하면 특정한 기준광 선의 근축광학적 특성을 유지시키면서 곡률과 축상두께가 다른 렌즈로 변환할 수 있다. 두꺼운 렌즈에서 축상두께만 변경하면 뒷면의 입사고와 근축각이 변화하면서 렌즈 전체 의 굴절능, 횡배율과 각배율, 그리고 3차 수차가 변화하게 된 다. 등가렌즈 변환은 렌즈 전체의 굴절능과 특정한 근축광선 에 대하여 굴절불변량과 근축각을 유지시킬 수 있으므로 변 환된 두꺼운 렌즈(등가렌즈)의 수차는 변환전과 유사하다 ${ }^{[1,}$ ${ }^{2]}$. 등가렌즈 변환은 광학계의 초기설계나 설계의 국소적 변

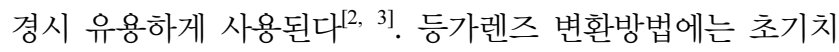

로서 주요점의 위치가 변환전과 같다고 근사하여 광선의 입 사고가 주어지면 각 면의 굴절능을 계산하고, 새로 계산된 주요점의 위치를 사용하여 면의 굴절능을 다시 계산하는 과 정을 반복하여 해에 수렴하게 하는 반복법이 사용되었다 ${ }^{[3,}$ ${ }^{4]}$. 최근에 등가렌즈 변환에서 근축광선이 주요면에 입사하는 높이와 전체굴절능은 변화하지 않는다는 것에 착안하여 등 가렌즈가 2 차 방정식의 해로서 주어지는 해석적인 등가렌즈 변환법이 발표된 바 있다리.

광학계에서는 물체는 상으로 결상하고, 입사동은 출사동으 로 결상한다. 축상물체점에서 출사하여 입사동의 끝단을 지 나 출사동의 끝단에서 축상 상점으로 입사하는 주변광선 (marginal ray, MR)은 물체의 결상을 대표하는 광선으로 볼 수 있고, 물체의 끝단에서 출사하여 입사동의 중심으로 입사 하고 출사동의 중심에서 출사하여 상의 끝단으로 입사하는

${ }^{\dagger}$ E-mail: julee@cju.ac.kr

Color versions of one or more of the figures in this paper are available online. 
주광선(chief ray, CR)은 동의 결상을 대표하는 광선으로 볼 수 있다.

등가렌즈 변환은 전체 굴절능의 변화 없이 특정한 기준 광 선에 대하여 근축광학적 특성을 유지시키는 것이다. 주변광 선(MR)을 기준으로 등가렌즈를 변환하면 주변광선의 근축 각 $u$ 와 굴절불변량 $A$ 는 변화하지 않으므로 두꺼운 렌즈 전 체의 횡배율과 각 면의 횡배율 모두 유지된다. 그러나 두꺼 운 렌즈 전체의 각배율은 유지되지만 주광선의 근축각 $\bar{u}$ 와 굴절불변량 $B$, 각 면의 각배율은 변화하게 된다 ${ }^{[4,}$ 5].

지금까지의 등가렌즈 변환은 주변광선을 기준으로 이루어 져 왔으며, 광학계의 주요한 용도가 물체를 상으로 결상시키 는 것이므로 당연한 것으로 볼 수 있다. 광학계에서 주변광 선이 축상 물체의 결상 특성을 나타낸다면 주광선은 비축 물 체의 결상을 나타낸다고 볼 수 있다 ${ }^{[5]}$. 따라서 넓은 시야를 가진 광학계의 등가렌즈 변환에서는 주광선을 기준으로 하 는 것이 주변광선보다 적절할 수도 있다. 이 연구에서는 두 꺼운 렌즈를 주광선을 기준으로 축상두께가 다른 등가렌즈 로 변환하고, 이를 기존의 경우와 같이 주변광선을 기준으로 하는 경우와 비교하였다. 등가렌즈 변환 결과를 비교하는 예 제 광학계로는 1 매의 결상 렌즈와 1 매의 field flattener로 구 성된 2매 렌즈계(Sample Lens 1)와 laser 주사광학계(Sample Lens 2)가 사용되었다. Sample lens 1에서 앞쪽의 결상 렌즈 $\mathrm{L}_{1}$ 은 주변광선의 입사고가 높고 주광선의 입사고가 낮은 예 이며, 뒤쪽의 field flattener $\mathrm{L}_{2}$ 는 주변광선의 입사고가 낮고 주광선의 입사고가 큰 렌즈의 예이다. Laser 주사광학계는 f수가 크고 시야각이 넓어 광학계 전체적으로 주변광선의 입 사고가 낮고 주광선의 입사고가 높은 예이다.

\section{II. 단렌즈의 결상과 등가렌즈 변환}

\section{1. 단렌즈의 결상과 Seidel 수차}

광학계에는 물체의 결상과 동의 결상이 존재하며, 각각의 결상은 주변광선과 주광선을 기준으로 이루어진다.

그림 1 에는 물체의 결상과 동의 결상이 동시에 일어나는 단렌즈와 주변광선 및 주광선이 나타나 있다. 주변광선은 유 한거리에 있는 축상물체점에서 출사하여 조리개의 끝단을 지나 축상상점으로 결상하고 있으며, 주광선은 광학결상의 기준광선으로서 물체의 끝단에서 출사하여 조리개의 중심을 지나 상의 끝단에서 결상하고 있다. 이 그림에서의 조리개는

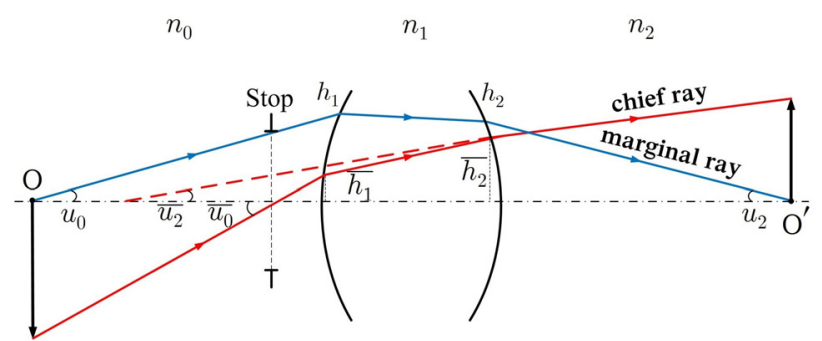

입사동이며, 입사동과 출사동은 공액관계(물체와 상의 관계) 를 이루고 있다. 이 그림에는 주변광선과 주광선이 각 렌즈 면에 입사하는 높이 $\left(h_{1}, h_{2}, \overline{h_{1}}, \overline{h_{2}}\right)$ 가 나타나 있으며, 굴절률 $\left(n_{0}, n_{1}, n_{2}\right)$ 와 근축각 $\left(u_{0}, u_{2}, \overline{u_{0}}, \overline{u_{2}}\right)$ 는 굴절후의 물리량이 다 ${ }^{[6]}$. 광학계의 Seidel 수차는 각 면에 입사하는 광선의 입사 고 $\left(h_{i}, \overline{h_{i}}\right)$, 매질의 굴절률 $\left(n_{i-1}, n_{i}\right)$, 근축각 $\left(u_{i-1}, \overline{u_{i}}\right)$ 의 함 수로 표현되며, 광학계의 Seidel 수차의 계수는 다음과 같이 주어진다 $\left.{ }^{[7,} 8\right]$

$$
\begin{aligned}
& S_{I}=-\sum_{i} A_{i}^{2} h_{i} \Delta\left(\frac{u}{n}\right)_{i}, \Delta\left(\frac{u}{n}\right)_{i}=\frac{u_{i}}{n_{i}}-\frac{u_{i-1}}{n_{i-1}} \\
& S_{I I}=-\sum_{i} A_{i} B_{i} h_{i} \Delta\left(\frac{u}{n}\right)_{i} \\
& S_{I I I}=-\sum_{i} B_{i}^{2} h_{i} \Delta\left(\frac{u}{n}\right)_{i} \\
& S_{I V}=H^{2} \sum_{i} P_{i}, P_{i}=-\frac{1}{r_{i}}\left(\frac{1}{n_{i}}-\frac{1}{n_{i-1}}\right) \\
& S_{V}=\sum_{i} \frac{B_{i}}{A_{i}}\left\{-B_{i}^{2} h_{i} \Delta\left(\frac{u}{n}\right)_{i}+H^{2} P_{i}\right\} \\
& C_{L}=\sum_{i} A_{i} h_{i} \Delta\left(\frac{\delta n}{n}\right)_{i}
\end{aligned}
$$

$$
C_{T}=\sum_{i} B_{i} h_{i} \Delta\left(\frac{\delta n}{n}\right)_{i}
$$

위 식에서 $A_{i}, B_{i}$ 는 주변광선의 굴절불변량과 주광선의 굴절불변량이며, $P_{i}$ 는 Petzval sum, $H$ 는 Lagrange 불변량이 다. 그림 1 에서 주변광선의 굴절불변량 $A_{1}, A_{2}$ 와 주광선의 굴절불변량 $B_{1}, B_{2}$ 는

$$
\begin{aligned}
& A_{1}=n_{0}\left(u_{0}+\frac{h_{1}}{r_{1}}\right)=n_{1}\left(u_{1}+\frac{h_{1}}{r_{1}}\right) \\
& A_{2}=n_{1}\left(u_{1}+\frac{h_{2}}{r_{2}}\right)=n_{2}\left(u_{2}+\frac{h_{2}}{r_{2}}\right) \\
& B_{1}=n_{0}\left(\overline{u_{0}}+\frac{\overline{h_{1}}}{r_{1}}\right)=n_{1}\left(\overline{u_{1}}+\frac{\overline{h_{1}}}{r_{1}}\right)
\end{aligned}
$$

FIG. 1. Optical layout of a thick lens system. 


$$
B_{2}=n_{1}\left(\overline{u_{1}}+\frac{\overline{h_{2}}}{r_{2}}\right)=n_{2}\left(\overline{u_{2}}+\frac{\overline{h_{2}}}{r_{2}}\right)
$$

로 나타낼 수 있다.

\section{2. 주변광선을 기준으로 한 등가렌즈 변환}

그림 2는 단렌즈에서 주변광선의 경로와 물체의 결상을 보 여주고 있으며, 주변광선의 근축각 $\left(u_{0}, u_{2}\right)$ 와 주요면에 입사 한 높이 $h$ 가 나타나 있다.

축상두께 $d_{1}$ 의 단렌즈를 축상두께 $d_{1}^{*}$ 의 등가렌즈로 변환 하고, 변환된 등가렌즈의 물리량은 위첨자 *를 붙여 표시하 도록 하자. 등가렌즈 변환에서는 광학계의 전체 굴절능, 주 변광선과 주광선이 주요면에 입사한 높이, 기준광선의 근축 각과 굴절불변량은 유지된다. 주변광선을 기준으로 한 등가 렌즈 변환의 조건은 다음과 같다.

$$
\begin{aligned}
& u_{0}^{*}=u_{0}, u_{1}^{*}=u_{1}, u_{2}^{*}=u_{2} \\
& A_{1}^{*}=A_{1}, A_{2}^{*}=A_{2}
\end{aligned}
$$

등가렌즈의 해석적인 변환방법은 참고문헌 [2]에 소개되어 있으며, 주변광선을 기준으로 한 해석적인 등가렌즈 변환법 은 다음과 같이 정리할 수 있다.

$$
\begin{aligned}
& \frac{n_{2} u_{2} d_{1}^{*}}{n_{1} K_{T}} k_{1}^{* 2}+\left(h-d_{1}^{*} u_{1}\right) k_{1}^{*}+n_{1} u_{1}-n_{0} u_{0}=0 \\
& k_{2}^{*}=\frac{n_{1} u_{1} K_{T}-n_{2} u_{2} k_{1}^{*}}{n_{0} u_{0}}
\end{aligned}
$$

등가렌즈는 식 (14)에 나타난 2차방정식의 해이며, 판별식 $D^{*}$ 의 부호에 따라 해가 없을 수도 있고 최대 2 개의 실근을 가질 수 있다.

$$
D^{*} \equiv\left(h-d_{1}^{*} u_{1}\right)^{2}-\frac{4 n_{2} u_{2} d_{1}^{*}\left(n_{1} u_{1}-n_{0} u_{0}\right)}{n_{1} K_{T}}
$$

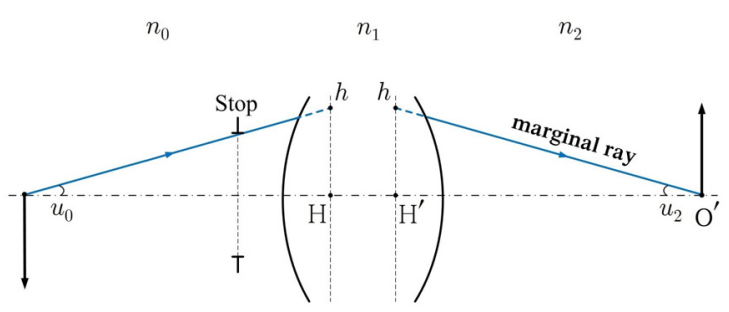

FIG. 2. Marginal ray of a thick lens system.

$$
\begin{aligned}
& k_{1+}^{*}=\frac{\left(-h+d_{1}^{*} u_{1}+\sqrt{D^{*}}\right) n_{1} K_{T}}{2 n_{2} u_{2} d_{1}^{*}} \\
& k_{1-}^{*}=\frac{\left(-h+d_{1}^{*} u_{1}-\sqrt{D^{*}}\right) n_{1} K_{T}}{2 n_{2} u_{2} d_{1}^{*}}
\end{aligned}
$$

$D^{*}>0$ 인 경우 식 (14)는 식 (17), (18)과 같이 2개의 해가 가 능하지만, 식 (18)의 해는 렌즈의 모양이 서로 다른 conjugate lens이며 ${ }^{[2]}$, 이 연구에서는 렌즈의 형태가 유사한 식 (17)의 해만 사용하였다,

\section{3. 주광선을 기준으로 한 등가렌즈 변환}

그림 3은 주광선의 경로를 보여주고 있다. 주광선은 동의 결상을 대표하는 광선으로서 입사동의 중심으로 입사하여 출사동의 중심에서 출사하고 있으며, 이 그림에는 주광선의 근 축각 $\left(\overline{u_{0}}, \overline{u_{2}}\right)$ 와 주요면에 입사하는 높이 $\bar{h}$ 가 나타나 있다.

두께 $d_{1}$ 의 두꺼운 렌즈를 주광선을 기준으로 두께 $d_{1}^{*}$ 의 등가렌즈로 변환하고, 등가렌즈의 물리량은 *를 붙여 표시하 도록 하자. 주광선을 기준으로 하는 등가렌즈 변환의 조건은 다음과 같다.

$$
\begin{aligned}
& \bar{u}_{0}^{*}=\overline{u_{0}}, \bar{u}_{1}^{*}=\overline{u_{1}}, \bar{u}_{2}^{*}=\overline{u_{2}} \\
& B_{1}^{*}=B_{1}, B_{2}{ }^{*}=B_{2}
\end{aligned}
$$

주광선을 기준으로 한 등가렌즈 변환은 다음과 같은 2 차방 정식과 선형방정식으로 주어진다.

$$
\begin{aligned}
& \frac{n_{2} \overline{u_{2}} d_{1}^{*}}{n_{1} K_{T}} k_{1}^{* 2}+\left(\bar{h}-d_{1}^{*} \overline{u_{1}}\right) k_{1}^{*}+n_{1} \overline{u_{1}}-n_{0} \overline{u_{0}}=0 \\
& k_{2}^{*}=\frac{n_{1} \overline{u_{1}} K_{T}-n_{2} \overline{u_{2}} k_{1}^{*}}{n_{0} \overline{u_{0}}}
\end{aligned}
$$

식 (21)의 2 차방정식은 판별식 $D^{*}$ 의 부호에 최대 2 개의 실근을 가질 수 있다.

$$
D^{*} \equiv\left(\bar{h}-d_{1}^{*} \overline{u_{1}}\right)^{2}-\frac{4 n_{2} \overline{u_{2}} d_{1}^{*}\left(n_{1} \overline{u_{1}}-n_{0} \overline{u_{0}}\right)}{n_{1} K_{T}}
$$

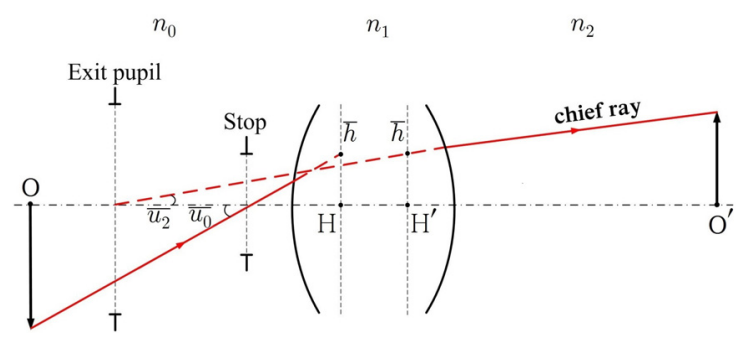

FIG. 3. Chief ray of a thick lens system. 


$$
\begin{aligned}
& k_{1+}^{*}=\frac{\left(-\bar{h}+d_{1}^{*} \overline{u_{1}}+\sqrt{D^{*}}\right) n_{1} K_{T}}{2 n_{2} \overline{u_{2}} d_{1}^{*}} \\
& k_{1-}^{*}=\frac{\left(-\bar{h}+d_{1}^{*} \overline{u_{1}}-\sqrt{D^{*}}\right) n_{1} K_{T}}{2 n_{2} \overline{u_{2}} d_{1}^{*}}
\end{aligned}
$$

$D^{*}>0$ 일 때 식 (25)는 참고문헌 [2]의 conjugate lens이며, 이 연구에서는 렌즈의 형태가 유사한 식 (24)의 $k_{1+}^{*}$ 을 등가 렌즈로 사용하였다.

\section{III. 등가렌즈 변환 사례검토}

\subsection{Sample Lens 1:2매 렌즈계}

등가렌즈 변환에서 기준광선의 선택에 따른 등가렌즈의 특 성 변화를 살펴보기 위하여 주변광선과 주광선의 광경로가
뚜렷하게 차이가 나는 그림 4의 2매 렌즈계를 등가렌즈 변환 의 첫 번째 예제렌즈(Sample Lens 1)로 사용하였다. 앞의 렌 즈 $\mathrm{L}_{1}$ 은 주변광선의 입사고가 높고, 주광선의 입사고가 낮은 렌즈이며, 뒤의 렌즈 $\mathrm{L}_{2}$ 는 반대로 주변광선의 입사고가 낮고 주광선의 입사고가 높은 렌즈이다. 이 연구에서는 주변광선

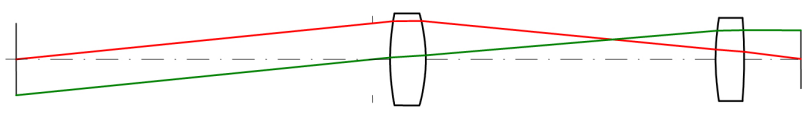

(a)

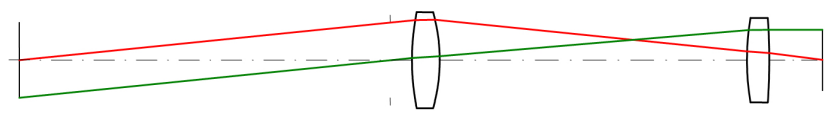

(b)

FIG. 4. Optical layouts of the sample lens 1 and it's equivalent lens. (a) Sample lens 1, (b) Equivalent lens EL 1A.

TABLE 1. Design data of the sample lens 1 and it's equivalent lenses (EL 1A, EL 1B)

\begin{tabular}{c|c|c|c|c|c|c|c}
\hline \hline & \multicolumn{3}{|c|}{ Sample Lens 1 } & \multicolumn{2}{c|}{ Equivalent Lens 1A } & \multicolumn{2}{c}{ Equivalent Lens 1B } \\
\hline Surface \# & $r(\mathrm{~mm})$ & $d(\mathrm{~mm})$ & $n$ & $r^{*}(\mathrm{~mm})$ & $d^{*}(\mathrm{~mm})$ & $r^{*}(\mathrm{~mm})$ & $d^{*}(\mathrm{~mm})$ \\
\hline 0 & - & 100.000 & & - & 100.000 & - & 100.000 \\
\hline 1 (stop) & - & 5.000 & & - & 5.886 & 5.623 \\
\hline 2 & 50.000 & 10.000 & 1.500 & 50.422 & 7.500 & 56.225 & 7.500 \\
\hline 3 & -50.000 & 81.362 & & -50.463 & 82.804 & -45.761 & 82.940 \\
\hline 4 & 70.000 & 8.000 & 1.500 & 67.226 & 6.000 & 70.317 & 6.000 \\
\hline 5 & -150.000 & 7.278 & & -166.619 & 8.084 & -150.000 & 8.211 \\
\hline 6 & - & & & - & & & - \\
\hline
\end{tabular}

$\mathrm{EFL}=80.843 \mathrm{~mm}, \mathrm{NA}=0.1, \mathrm{FOV}=11.42^{\circ}, u_{0}=0.1, \overline{u_{0}}=0.1$

\begin{tabular}{|c|c|c|c|c|c|c|}
\hline & Lens & \multicolumn{2}{|c|}{$\mathrm{L}_{1}$} & \multicolumn{2}{|c|}{$\mathrm{L}_{2}$} & \multirow{2}{*}{ Sum } \\
\hline & Surface \# & 2 & 3 & 4 & 5 & \\
\hline \multirow{3}{*}{$S_{I}$} & Sample Lens 1 & 0.103147 & 0.114439 & -0.000664 & 0.001061 & 0.217983 \\
\hline & EL 1A & 0.104017 & 0.115499 & -0.000638 & 0.001178 & 0.220057 \\
\hline & EL 1B & 0.085159 & 0.138519 & -0.000657 & 0.001214 & 0.224234 \\
\hline \multirow{3}{*}{$S_{I I}$} & Sample Lens 1 & 0.036601 & -0.021883 & 0.001494 & 0.000441 & 0.016652 \\
\hline & EL $1 \mathrm{~A}$ & 0.037471 & -0.022692 & 0.001474 & 0.000441 & 0.016694 \\
\hline & EL 1B & 0.032542 & -0.024769 & 0.001465 & 0.000501 & 0.009740 \\
\hline \multirow{3}{*}{$S_{I I I}$} & Sample Lens 1 & 0.012987 & 0.004185 & -0.003360 & 0.000183 & 0.013995 \\
\hline & EL 1A & 0.013498 & 0.004458 & -0.003406 & 0.000165 & 0.014716 \\
\hline & EL 1B & 0.012435 & 0.004429 & -0.003268 & 0.000207 & 0.013804 \\
\hline \multirow{3}{*}{$S_{I V}$} & Sample Lens 1 & 0.006667 & 0.006667 & 0.004762 & 0.002222 & 0.020317 \\
\hline & EL 1A & 0.006611 & 0.006606 & 0.004958 & 0.002001 & 0.020175 \\
\hline & EL 1B & 0.005929 & 0.007284 & 0.004740 & 0.002222 & 0.020175 \\
\hline \multirow{3}{*}{$S_{V}$} & Sample Lens 1 & 0.006974 & -0.002075 & -0.003153 & 0.001000 & 0.002746 \\
\hline & EL 1A & 0.007244 & -0.002174 & -0.003588 & 0.000810 & 0.002292 \\
\hline & EL 1B & 0.007018 & -0.002094 & -0.003284 & 0.001004 & 0.002643 \\
\hline
\end{tabular}

TABLE 2. Seidel aberrations of the sample lens 1 and it's equivalent lenses (EL 1A, EL 1B) 
을 기준으로 변환된 등가렌즈는 EL 1A(equivalent lens 1A), 주광선을 기준으로 변환된 등가렌즈는 $\mathrm{EL} 1 \mathrm{~B}$ (equivalent lens 1B)로 표시하였다.

2 매 렌즈계의 두께를 $75 \%$ 로 줄이는 과정에서 등가렌즈 변 환법을 적용하였으며, Sample Lens 1과 등가렌즈 EL 1A, $\mathrm{EL} \mathrm{1B}$ 에 대한 설계 제원은 표 1에 나타나 있다.

원래의 설계는 초점거리 $80.843 \mathrm{~mm}, \mathrm{NA} 0.1, \mathrm{FOV} 11.42^{\circ}$ 이고 횡배율이 -0.8 인 렌즈계이며, 등가렌즈 변환을 통해 곡 률반경과 면간의 간격이 변화한 것을 볼 수 있다.

표 2에는 Sample Lens 1과 이의 등가렌즈 EL 1A, EL 1B 의 Seidel 수차가 정리되어 있다. 변환 결과에 대한 Seidel 수 차를 비교해보면 $S_{I}$ 의 경우, $\mathrm{EL} 1 \mathrm{~A}$ 의 수차 변화가 주광선 을 기준으로 한 $\mathrm{EL} 1 \mathrm{~B}$ 보다 적었다. 앞의 렌즈 $\mathrm{L}_{1}$ 과 뒤의 렌 즈 $\mathrm{L}_{2}$ 모두 같은 경향을 보여 주변광선과 주광선의 입사고에 는 영향을 받지 않는 것으로 보인다. $S_{I I}$ 의 경우에서도 $\mathrm{EL}$ $1 \mathrm{~A}$ 가 $\mathrm{EL} 1 \mathrm{~B}$ 보다 수차 변화가 적었으며, 렌즈 별로 비교하 여도 같은 경향을 보였다. $S_{I I I}$ 에서는 $\mathrm{L}_{1}$ 의 수차 기여분이 가장 크고 $\mathrm{EL} 1 \mathrm{~A}$ 보다 $\mathrm{EL} 1 \mathrm{~B}$ 에서 수차 변화가 더욱 적게 일 어나는 것을 알 수 있으며, 전체 수차에서도 EL 1A보다 EL $1 \mathrm{~B}$ 가 원래의 설계에 잘 근사하고 있음을 확인할 수 있다. $S_{I V}$ 에서 $\mathrm{L}_{1}$ 은 EL $1 \mathrm{~A}$ 가 EL $1 \mathrm{~B}$ 보다 수차 변화가 적으며, $\mathrm{L}_{2}$ 는 EL $1 \mathrm{~B}$ 가 EL $1 \mathrm{~A}$ 보다 수차 변화가 적게 발생하였다. 각 렌즈에서 기준광선의 선택에 의한 등가렌즈의 수차 특성이
뚜렷하게 나타나고 있다. $S_{V}$ 의 경우에는 $\mathrm{L}_{1}, \mathrm{~L}_{2}$ 모두에서 $\mathrm{EL} 1 \mathrm{~B}$ 의 수차 변화가 적은 것을 알 수 있다.

기준광선의 선택에 따른 등가렌즈의 Seidel 수차를 비교해 보면 $S_{I}$ 과 $S_{I I}$ 는 $\mathrm{EL} 1 \mathrm{~A}$ 의 수차 변화가 적어 원래 설계의 특성을 잘 근사하고 있으며, $S_{I I I}$ 와 $S_{V}$ 에서는 $\mathrm{EL} 1 \mathrm{~B}$ 의 수차 변화가 EL 1A보다 적고 수차 특성이 원래의 설계와 매우 유 사함을 볼 수 있다. $S_{I V}$ 는 주변광선의 입사고가 높은 $\mathrm{L}_{1}$ 에서 $\mathrm{EL} 1 \mathrm{~A}$ 가 보다 수차 변화가 적었고, 주광선의 입사고가 높은 $\mathrm{L}_{2}$ 는 $\mathrm{EL} 1 \mathrm{~B}$ 의 수차 변화가 적어 기준 광선의 입사고가 영향 을 준다고 볼 수 있다. 2매 렌즈로 구성된 Sample Lens 1의 등가렌즈 변환에서 기준광선의 선택에 따른 Seidel 수차의 변화는 각 렌즈로 입사하는 광선의 높이보다는 수차의 종류 에 의존하는 것으로 보인다. 따라서 이 특성을 활용한다면 f수는 작고 시야가 좁은 광학계에서는 $S_{I}$ 과 $S_{I I}$ 의 변화가 적 은 주변광선을 기준으로 한 등가렌즈 변환이 유리하고, 반면 에 f-수가 크고 넓은 시야를 가진 광학계에서는 $S_{I I I}$ 와 $S_{V}$ 의 변화가 적은 주광선을 기준으로 하는 변환이 보다 유용한 것 으로 볼 수 있다.

\subsection{Sample Lens 2: 광각 Laser 주사광학계}

앞 절의 Sample Lens 1에 대한 등가렌즈 변환에서 주광선 을 기준으로 변환하면 $S_{I I I}, S_{V}$ 의 변화가 적음을 볼 수 있 었다. 이 절에서는 앞 절의 분석결과를 확인하기 위하여 f-수

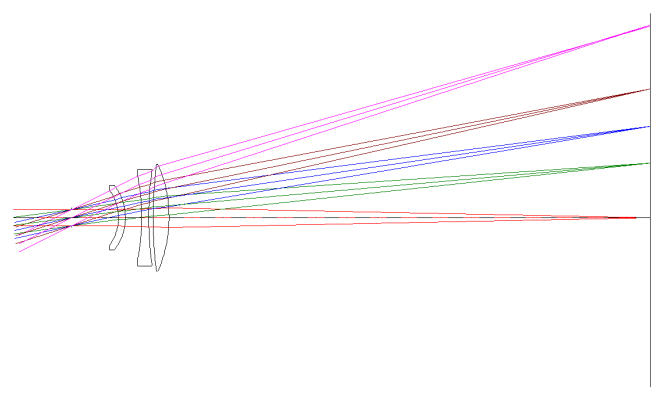

(b)

FIG. 5. Optical layouts of the sample lens 2 and it's equivalent lens. (a) Sample lens 2, (b) Equivalent lens EL 2A.

TABLE 3. Design data of the sample lens 2 and it's equivalent lenses (EL 2A, EL 2B)

\begin{tabular}{c|c|c|c|c|c|c|c}
\hline \hline & \multicolumn{3}{|c|}{ Sample Lens 2 } & \multicolumn{2}{c|}{ Equivalent Lens 2A } & \multicolumn{2}{c}{ Equivalent Lens 2B } \\
\hline Surface \# & $r(\mathrm{~mm})$ & $d(\mathrm{~mm})$ & $n$ & $r^{*}(\mathrm{~mm})$ & $d^{*}(\mathrm{~mm})$ & $r^{*}(\mathrm{~mm})$ & $d^{*}(\mathrm{~mm})$ \\
\hline 1 (stop) & - & 72.000 & & - & 58.063 & - & 65.870 \\
\hline 2 & -56.661 & 10.000 & 1.754 & -56.661 & 8.500 & -51.837 & -5.500 \\
\hline 3 & -64.226 & 3.000 & & -63.546 & 20.159 & -58.199 & 11.280 \\
\hline 4 & -255.834 & 10.000 & 1.644 & -255.888 & 8.500 & -256.799 & 8.500 \\
\hline 5 & 412.623 & 3.310 & & 411.549 & 5.393 & 409.227 & 5.369 \\
\hline 6 & 494.737 & 23.200 & 1.754 & 498.183 & 19.720 & 504.842 & 19.720 \\
\hline 7 & -163.143 & 591.809 & & -163.286 & 592.327 & -162.608 & 592.364 \\
\hline 8 & - & & & - & & & - \\
\hline
\end{tabular}


TABLE 4. Seidel aberrations of the sample lens 2 and it's equivalent lenses (EL 2A, EL 2B)

\begin{tabular}{|c|c|c|c|c|c|c|c|c|}
\hline & Lens & \multicolumn{2}{|c|}{$\mathrm{L}_{1}$} & \multicolumn{2}{|c|}{$\mathrm{L}_{2}$} & \multicolumn{2}{|c|}{$\mathrm{L}_{3}$} & \multirow{2}{*}{ Sum } \\
\hline & Surface \# & 2 & 3 & 4 & 5 & 6 & 7 & \\
\hline \multirow{3}{*}{$S_{I}$} & Sample Lens 2 & -0.013473 & 0.010143 & -0.000078 & -0.002549 & 0.002413 & 0.002930 & -0.000614 \\
\hline & EL 2A & -0.013473 & 0.010036 & -0.000078 & -0.002542 & 0.002430 & 0.002932 & -0.000695 \\
\hline & EL 2B & -0.017595 & 0.013613 & -0.000077 & -0.002554 & 0.002405 & 0.002959 & -0.001249 \\
\hline \multirow{3}{*}{$S_{I I}$} & Sample Lens 2 & -0.010080 & 0.009635 & 0.000693 & -0.025143 & 0.024664 & 0.000424 & 0.000195 \\
\hline & EL 2A & -0.000921 & 0.002043 & 0.000692 & -0.025057 & 0.024880 & 0.000382 & 0.002018 \\
\hline & EL 2B & -0.012043 & 0.011732 & 0.000686 & -0.025147 & 0.024685 & 0.000427 & 0.000340 \\
\hline \multirow{3}{*}{$S_{I I I}$} & Sample Lens 2 & -0.007541 & 0.009153 & -0.006165 & -0.248031 & 0.252124 & 0.000061 & -0.000399 \\
\hline & EL 2A & -0.000063 & 0.000416 & -0.006143 & -0.246995 & 0.254783 & 0.000050 & 0.002048 \\
\hline & EL 2B & -0.008243 & 0.010112 & -0.006128 & -0.247601 & 0.253370 & 0.000062 & 0.001571 \\
\hline \multirow{3}{*}{$S_{I V}$} & Sample Lens 2 & -0.180481 & 0.159223 & -0.036414 & -0.022577 & 0.020670 & 0.062683 & 0.003104 \\
\hline & EL 2A & -0.180481 & 0.160925 & -0.036406 & -0.022636 & 0.020527 & 0.062628 & 0.004557 \\
\hline & EL 2B & -0.197276 & 0.175712 & -0.036277 & -0.022764 & 0.020256 & 0.062889 & 0.002540 \\
\hline \multirow{3}{*}{$S_{V}$} & Sample Lens 2 & -0.140668 & 0.159945 & 0.378877 & -2.669537 & 2.788563 & 0.009090 & 0.526269 \\
\hline & EL 2A & -0.012348 & 0.032850 & 0.377880 & -2.657792 & 2.819284 & 0.008157 & 0.568031 \\
\hline & EL 2B & -0.140668 & 0.160156 & 0.378935 & -2.662015 & 2.808563 & 0.009089 & 0.554060 \\
\hline
\end{tabular}

가 크고 시야각이 넓은 예제렌즈 2(Sample Lens 2)를 사용하 여, 주변광선을 기준으로 변환한 등가렌즈 EL 2A와 주광선 을 기준으로 변환한 등가렌즈 EL 2B의 Seidel 수차를 비교 하였다. 그림 5 의 예제렌즈 2 는 laser 주사광학계이며, 등가 렌즈 변환에서 렌즈의 두께를 원설계의 $85 \%$ 로 줄였다. Sample Lens 2 와 등가렌즈 EL 2A, EL 2B의 설계 제원은 표 3 에 정리되어 있다.

그림 5의 (a)는 원래의 주사광학계이며, 그림 5(b)에는 주 변광선을 기준으로 등가렌즈로 변환된 광학계 $\mathrm{EL} 2 \mathrm{~A}$ 가 나 타나 있다. 등가렌즈 EL $2 \mathrm{~A}$ 와 EL $2 \mathrm{~B}$ 의 모양은 거의 같다. Sample Lens 2의 원설계와 등가렌즈 EL 2A, EL 2B의 Seidel 수차는 표 4에 정리되어 있다.

Sample Lens 2의 등가렌즈 변환에서 $S_{I}$ 은 예상과 같이 EL $2 \mathrm{~A}$ 의 수차 변화가 $\mathrm{EL} 2 \mathrm{~B}$ 보다 적고 원래의 설계와 매우 유 사함을 확인할 수 있다. $S_{I I I}, S_{V}$ 의 경우에도 $\mathrm{EL} 2 \mathrm{~B}$ 의 수차 변화가 EL $2 \mathrm{~A}$ 보다 적어 원래 설계의 수차 특성을 잘 근사하 고 있다. $S_{I I}$ 의 경우에는 앞의 Sample Lens 1 의 경우와는 달리 EL 2B가 EL 2A보다 수차의 변화가 작다. 이것을 표 4 에서 각 면단위로 상세하게 살펴보면 $S_{I I}$ 의 발생이 큰 제5 면과 제 6 면에서 EL $2 \mathrm{~B}$ 의 수차 변화가 작기 때문이며, 제 5 면 과 제6면은 다른 면과 비교하여 주광선의 굴절불변량 $B$ 가 $A$ 보다 약 10 배 정도 큰 공통점이 있었다. 이것은 식 (2)의 Seidel 수차식과 일치한다. 앞서의 Sample Lens 1에서는 광 학계 전체적으로 주변광선의 굴절불변량 $A$ 가 주광선의 굴절 불변량 $B$ 보다 큰 값을 가졌기 때문에 $\mathrm{EL} 1 \mathrm{~A}$ 가 EL $1 \mathrm{~B}$ 보다 $S_{I I}$ 의 변화가 적었으나, Sample Lens 2의 경우는 광각의 주 사광학계여서 주광선의 굴절불변량 $B$ 가 주변광선의 굴절불 변량 $A$ 보다 큰 면이 많았기 때문에 EL $2 \mathrm{~B}$ 가 EL $2 \mathrm{~A}$ 보다 원
래의 $S_{I I}$ 를 잘 근사하고 있는 것으로 이해된다. $S_{I V}$ 의 경우, 각 면의 수차 기여분만 비교하면 EL $2 \mathrm{~A}$ 가 EL $2 \mathrm{~B}$ 보다 수차 변화가 적게 일어나고 있으나 광학계 전체의 수차는 EL 2B 의 변화가 적었다. 이것을 상세하게 분석하여 보면 주변광선 을 기준으로 변환한 $\mathrm{EL} 2 \mathrm{~A}$ 는 각 면에서의 변화가 주로 '+' 방향으로 발생하여 전체의 합이 원설계보다 커진 반면, 주광 선을 기준으로 변환한 $\mathrm{EL} 2 \mathrm{~B}$ 에서는 면 단위의 변화는 크지 만 ‘+' 방향의 변화와 '-' 방향의 변화가 서로 상쇄하여 광학계 전체적으로는 변화가 더 적은 것으로 나타나고 있다.

광각 laser 주사광학계의 등가렌즈 변환에서 $S_{I}$ 은 EL $2 \mathrm{~A}$ 의 수차 변화가 적었으며, 비축 수차는 $\mathrm{EL} 2 \mathrm{~B}$ 의 수차 변화 가 적게 일어나 원래 설계의 수차 특성을 잘 근사하였다. 이 를 통해서 넓은 시야를 가진 광학계에서는 주광선을 기준으 로 한 등가렌즈 변환이 주변광선을 기준으로 한 등가렌즈의 변환보다 더욱 유리한 것을 확인할 수 있었다.

\section{IV. 결 론}

광학설계에서 등가렌즈는 축상두께는 다르지만 전체 굴절 능과 근축광학적 특성이 같고 수차 특성이 유사한 렌즈를 의 미한다. 광학계는 물체의 결상과 동의 결상이 동시에 일어나 고 있으며, 주변광선은 물체의 결상을 대표하고 주광선은 동 의 결상을 대표하는 광선으로 볼 수 있다. 지금까지의 등가 렌즈 변환은 주변광선을 기준으로 하는 등가렌즈 변환법이 적용되어 왔었다. 이 연구에서는 2 종의 예제렌즈를 주광선을 기준으로 등가렌즈로 변환하고 주변광선을 기준으로 하는 기존의 등가렌즈 변환과의 차이점을 분석하였다.

주변광선의 입사고가 높고 주광선의 입사고가 낮은 1 번 렌 즈와 주변광선의 입사고가 낮고 주광선의 입사고가 높은 2 
번 렌즈로 구성된 2매 광학계의 등가렌즈 변환에서는 $S_{I}$ 과 $S_{I I}$ 는 주변광선을 기준으로 변환한 경우가 수차의 변화가 적었으며 $S_{I I I}, S_{V}$ 는 주광선을 기준으로 변환한 경우가 수 차의 변화가 적다. $S_{I V}$ 의 경우에는 주변광선의 입사고가 높 은 1 번 렌즈는 주변광선을 기준으로 한 경우가 수차 변화가 적었으며 주광선의 입사고가 높은 2 번 렌즈의 경우는 주광 선을 기준으로 한 경우가 수차 변화가 적었다. Seidel 수차식 을 살펴보면 주변광선의 굴절불변량 $A$ 의 제곱에 비례하는 $S_{I}$ 은 주변광선을 기준으로 변환하고, 주광선의 굴절불변량 $B$ 의 제곱에 비례하는 $S_{I I I}$ 와 $S_{V}$ 는 주광선을 기준으로 하는 것이 보다 적절한 것으로 예상되며 이것은 Sample Lens 1의 등가렌즈 변환 결과와 일치한다. $S_{I I}$ 의 경우는 Sample Lens 1 에서 전체적으로 주변광선의 굴절불변량 $A$ 가 주광선의 굴 절불변량 $B$ 보다 큰 면이 많았기에 주변광선을 기준으로 변 환한 경우가 수차의 변화가 적은 것으로 설명할 수 있다.

Sample Lens 2는 단순한 구조의 2매 광학계인 Sample Lens 1 에서 얻은 결과를 검증하기 위하여 f-수가 크고 시야 각이 넓은 laser 주사광학계를 선택하였다. Sample Lens 2의 등가렌즈 변환에서는 $S_{I}$ 은 예상과 같이 주변광선을 기준으 로 변환한 경우가 수차의 변화가 적었으나 비축수차인 $S_{I I}$, $S_{I I I}, S_{I V}, S_{V}$ 는 모두 주광선을 기준으로 한 등가렌즈 변환 이 수차의 변화가 적었다. Seidel 수차식과 2종의 Sample Lens의 등가렌즈 변환에서 얻어진 결과를 본다면 구면수차 의 보정이 중요한 f-수가 작고 시야가 좁은 광학계의 설계에 서는 주변광선을 기준으로 하는 등가렌즈 변환이 적절하며, 반대로 $\mathrm{f}$-수가 크고 시야가 넓은 광학계의 설계에서는 주광 선을 기준으로 하는 등가렌즈 변환이 적절할 것으로 볼 수 있다.

\section{감사의 글}

이 논문은 2012학년도 청주대학교 연구장학의 지원에 의 해 연구되었습니다.

\section{References}

1. Y. S. Chun, "A study on the design of optical system by using equivalent lens," Master's Thesis, Cheongju University (1999).

2. J. U. Lee, "A study for an analytic conversion between equivalent lenses," Korean J. Opt. Photon. (Hankook Kwanghak Hoeji) 23, 17-22 (2012).

3. J. U. Lee and K. S. Kim, "Generalization of equivalent lens conversion and third order aberration formulae of the generalized equivalent lens system," Korean J. Opt. Photon. (Hankook Kwanghak Hoeji) 7, 305-313 (1996).

4. J. U. Lee and S. C. Park, "Generalized lens group conversion to their equivalent lenses," Korean J. Opt. Photon. (Hankook Kwanghak Hoeji) 9, 251-257 (1998).

5. K. Miyake, Renzu Sekkeino Kenri (Japanese, Principles of Lens Design) (Kodansha, Tokyo, Japan, 1981), Chapter 8.

6. Y. S. Chun, H. S. Kim, and J. U. Lee, "Optical design of cemented doublets by using equivalent lens system," Korean J. Opt. Photon. (Hankook Kwanghak Hoeji) 9, 282-290 (1998).

7. W. T. Welford, Aberrations of the Symmetrical Optical System (Academic Press INC, London, UK, 1974), Chapter 7.

8. W. J. Smith, Modern Optical Engineering, 4th ed. (McGraw Hill, New York, USA, 2008), Chapter 6. 